\title{
Measles outbreak spreading from the community to an anthroposophic school, Berlin, 2011
}

\author{
S. GILLESBERG LASSEN ${ }^{1,2}$, M. SCHUSTER ${ }^{1}$, M. STEMMLER ${ }^{3}$, \\ A. STEINMÜLLER ${ }^{4}$, D. MATYSIAK-KLOSE ${ }^{1}$, A. MANKERTZ ${ }^{5}$, \\ S. SANTIBANEZ ${ }^{5}$, O. WICHMANN ${ }^{1}$ AND G. FALKENHORST ${ }^{1 *}$ \\ ${ }^{1}$ Robert Koch Institute, Department for Infectious Disease Epidemiology, Berlin, Germany \\ ${ }^{2}$ European Programme for Intervention Epidemiology Training (EPIET), European Centre for Disease \\ Prevention and Control, Stockholm, Sweden \\ ${ }^{3}$ District Public Health Authority, Berlin, Germany \\ ${ }^{4}$ Berlin, Germany \\ ${ }^{5}$ Robert Koch Institute, National Reference Centre Measles, Mumps, Rubella, Berlin, Germany
}

Received 27 September 2012; Final revision 26 April 2013; Accepted 17 May 2013; first published online 3 July 2013

\section{SUMMARY}

Between April and July 2011 there was an outbreak of measles virus, genotype D4, in Berlin, Germany. We identified 73 case-patients from the community and among students of an anthroposophic school, who participated in a 4-day school trip, as well as their family and friends. Overall, $27 \%$ were aged $\geqslant 20$ years, $57 \%$ were female and $15 \%$ were hospitalized. Of 39 community case-patients, $38 \%$ were aged $\geqslant 20$ years, $67 \%$ were female and $63 \%$ required hospitalization. Unvaccinated students returning from the school trip were excluded from school, limiting transmission. Within the group of 55 school-trip participants, including 20 measles case-patients, a measles vaccine effectiveness of $97 \cdot 1 \%(95 \%$ confidence interval $83 \cdot 4-100)$ for two doses was estimated using exact Poisson regression. Our findings support school exclusions and the recommendation of one-dose catch-up vaccination for everyone born after 1970 with incomplete or unknown vaccination status, in addition to the two-dose routine childhood immunization recommendation.

Key words: Community outbreak, infectious disease control, measles, MMR vaccination, vaccines.

\section{INTRODUCTION}

Measles has been targeted for elimination in the WHO European region since 1998 [1, 2]. Initially, progress towards the target was made. However, in Germany and several other member states, large measles outbreaks continued to occur [3] and increased transmission has been observed in Europe since late

\footnotetext{
* Author for correspondence: Dr G. Falkenhorst, Robert Koch Institute, DGZ-Ring 1, 13086 Berlin, Germany. (Email: FalkenhorstG@rki.de)
}

2009 [4-6]. Since 2001, suspected and confirmed measles cases in Germany must be notified by clinicians and laboratories according to the Protection against Infection Act. Reported national annual incidence rates during 2006-2010 ranged between 0.69 and $2 \cdot 80 / 100000$ population [7] with substantial overall decline since 2003 and interrupted transmission of indigenous measles virus (MV) variants [8]. Local and regional outbreaks have occurred sporadically since 2005 and since 2004 an increasing proportion of adult cases has been observed [8-10]. The last outbreak in Berlin was reported in 2010 consisting of 
62 reported cases [11]. The annual incidence from 2006 to 2010 in Berlin ranged between 0.23 and $2 \cdot 66 / 100000$ [7].

In 1970, the former German Democratic Republic (East Germany) introduced a mandatory one-dose measles vaccination programme for all children. Since 1974, The Federal Republic of Germany (West Germany) recommended one-dose measles vaccination. In the reunited Germany, two doses of measles-containing vaccine (MCV) have been recommended since 1991. Since 2001, the recommended age for vaccination is $11-14$ months (first dose) and 15-23 months (second dose) with opportunistic catch-up until age 18 years $[10,12]$. The national vaccination coverage assessed for children aged 5-6 years, using retrospective assessment at school entry, was $96.4 \%$ for one dose and $91.5 \%$ for two doses of MCV in 2010 [13]. In order to address the accumulation of adults susceptible to measles, as indicated by the increased proportion of notified adult measles cases, the vaccination recommendation was expanded in 2010 to include one MCV dose for all adults born after 1970 with unknown vaccination status, no vaccination or only one MCV dose during childhood $[10,14]$.

\section{Outbreak notification}

On 9 May 2011, the state public health authority requested the Robert Koch Institute (RKI) to support the investigation of an unusually high number of measles cases in district X, Berlin, Germany. The district is one of 12 districts in Berlin with about 250000 inhabitants. Fourteen case-patients had been notified to the district health authority of which 10 were laboratory-confirmed. The first case-patient had rash onset on 15 April 2011. District X had 0-9 measles cases per year from 2006 to 2010 [7] and school entry medical examinations of children aged 5-6 years indicated that the two-dose MCV (MCV2) coverage in district $\mathrm{X}$ was $88.5 \%$ in 2010 and $91 \cdot 1 \%$ in 2011.

The district health authority had identified two clusters of case-patients in area A that could be related or unrelated. One in the community of area A characterized by apartment blocks and a centrally located shopping centre and the other associated with a 4-day school trip (26-29 April 2011) taken by 55 students from an anthroposophic school located within area $\mathrm{A}$.
We aimed to describe the outbreak by time, place and person, to estimate vaccine effectiveness (VE), to identify risk groups, to formulate control measures, and to assess whether all cases were attributable to the same outbreak.

\section{METHODS}

We used structured questionnaires to interview casepatients in the community by telephone. The data was used to describe the case-patients by time, place, vaccination status, demographic and clinical factors. Additionally, we conducted a retrospective cohort study to calculate attack rates (ARs) in vaccinated and unvaccinated school-trip participants and to estimate VE. Differences in medians were tested using the Mann-Whitney test on a $5 \%$ significance level. The data were analysed using Stata (version 12.0, StataCorp LP, USA) and Excel 2003 (Microsoft Corporation, USA).

\section{Case definition}

We defined a probable case as a person presenting with a generalized rash for $>3$ days with fever and either cough, a runny nose, red eyes or Koplik's spots with symptom onset between 1 April and 31 July 2011 in people living, working or attending school in district X. We defined a confirmed case as a probable case with laboratory confirmation [detection of MV-specific IgM antibodies or MV genome using polymerase chain reaction (PCR)].

We classified a case-patient as a 'school-trip case' if the case-patient had participated in the school trip occurring on 26-29 April 2011. A case-patient not participating in the school trip was classified as a 'community case'.

We defined secondary cases as those occurring in contacts of a probable or confirmed case-patient for whom rash onset was 7-21 days after contact with the primary case.

\section{Case finding}

We used routine patient notifications made to the district health authority by doctors and laboratories. Using email and regular meetings other district health authorities in Berlin were asked about measles casepatients falling under the case definitions.

We searched actively for cases by (a) asking case-patients if they knew of others with measles, (b) reviewing data from the National Reference 


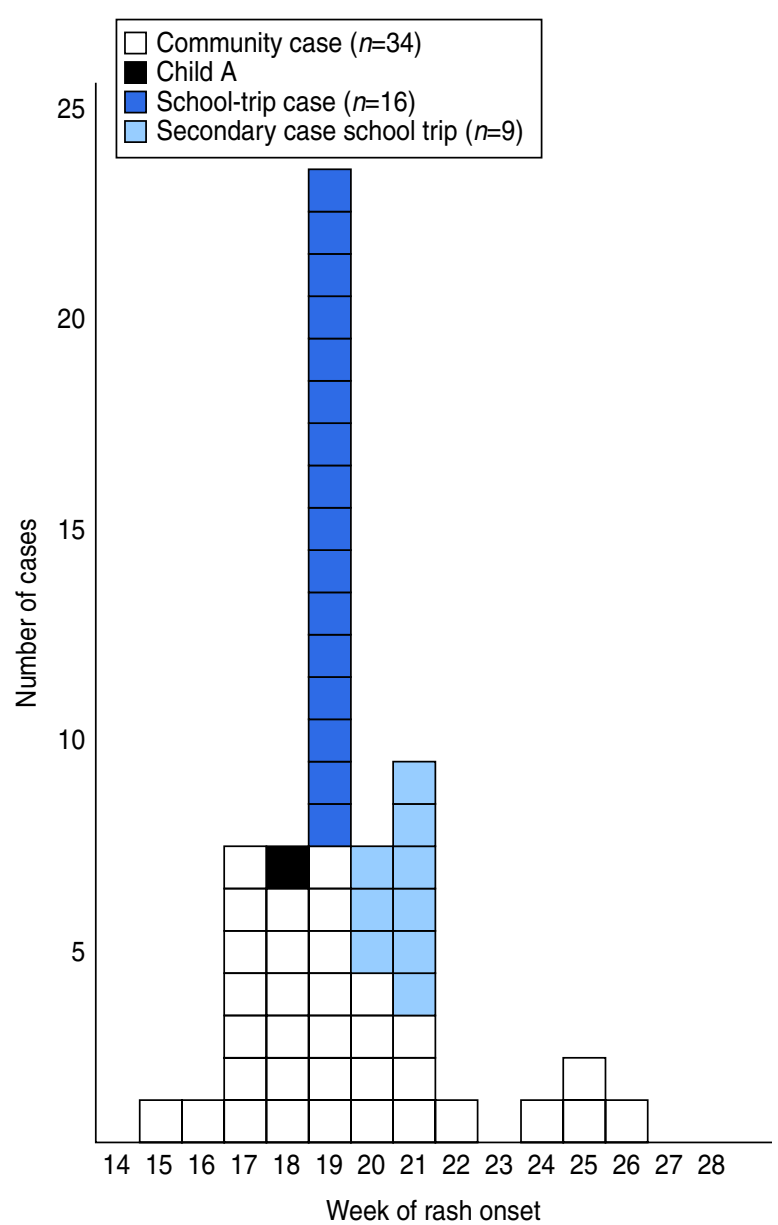

Fig. 1 [colour online]. Measles cases in the outbreak in district X, Berlin, Germany, 2011, by week of onset of rash $(n=60)$. Date of rash onset missing for 13 cases.

Laboratory and (c) sending letters to all local paediatricians, general practitioners, schools and nurseries. The school doctor identified school-trip cases by calling parents of all school-trip participants and children who reported ill to the school.

\section{Calculation of VE}

The school checked vaccination cards of all students and collected information on doses received of MCV and participation in the school trip on an anonymous form. Using exact Poisson regression, we calculated incidence rate ratios (IRR) and $\mathrm{VE}(\mathrm{VE}=1-\mathrm{IRR})$ with $95 \%$ confidence intervals $(\mathrm{CI})$ for one and two doses of MCV.

\section{Laboratory investigation}

The German National Reference Centre Measles, Mumps, Rubella (NRC) conducted laboratory confirmation of suspected cases and MV genotyping.
Private laboratories also performed serological testing. MV-specific IgM and IgG antibodies were determined in serum samples using commercially available enzyme-linked immunosorbent assays (ELISA, EUROIMMUN AG, Germany). MV genome was detected by reverse transcription (RT)-PCR, as described previously [15]. RT-PCR was performed on throat swabs, oral fluid and urine samples collected within 7 days after onset of exanthema. In addition to routine sample collection by treating physicians, members of the outbreak investigation team made home visits to collect throat swabs and urine samples.

Genotyping of detected MV was performed according to WHO recommendations [16] and has been described in detail previously $[17,18]$. The sequence data obtained, the genotype information, the official WHO MV sequence name, and relevant epidemiological data were submitted to GenBank and the WHO Measles Nucleotide Surveillance database (MeaNS, www.hpabioinformatics.org.uk/Measles/Public/Web_ Front/main.php).

\section{RESULTS}

\section{Outbreak description}

We identified a total of 73 measles case-patients; 35 probable and 38 confirmed cases. Of these, 39 were community case-patients, 20 were children who participated in the school trip, and 14 were friends or family members of the school-trip case-patients (Fig. 1). Of the 72 case-patients with known gender $41(57 \%)$ were female. Age was reported for 59 casepatients, $16(27 \%)$ were aged $\geqslant 20$ years of age. Of all case-patients, $11(15 \%)$ were hospitalized. The outbreak peaked in calendar week 19 (Fig. 1).

\section{Community cases}

The number of community case-patients peaked in calendar weeks 17-19 (Fig. 1). Of the 39 community case-patients, $26(67 \%)$ were female and $14(38 \%)$ were aged $\geqslant 20$ years (Fig. 2). Twelve of the $14 \mathrm{com}$ munity case-patients aged $\geqslant 20$ years were female. Three case-patients were aged $<1$ year. The overall median age was 14 years: for male cases it was 12 years (range $0-36$ ), while the median age of female cases was statistically significantly higher at 17 years (range $0-44)(P=0 \cdot 020)$. Of 16 community casepatients with available information, $10(63 \%)$ were hospitalized (three were aged $\leqslant 1$ year and seven were aged $\geqslant 20$ years). No deaths were reported. 
Table 1. Vaccination status of children participating in the school trip, district X measles outbreak, Berlin (Germany), 2011, and vaccine effectiveness, $2011(n=51)$

\begin{tabular}{lllll}
\hline \hline $\begin{array}{l}\text { No. of } \\
\text { vaccinations }\end{array}$ & $\begin{array}{l}\text { No. of children } \\
\text { with measles }\end{array}$ & $\begin{array}{l}\text { No. of children } \\
\text { without measles }\end{array}$ & $\begin{array}{l}\text { Vaccine } \\
\text { effectiveness (\%) }\end{array}$ & $95 \%$ CI \\
\hline 0 & 18 & 1 & Ref. & \\
1 & 0 & 6 & $87 \cdot 6$ & $28 \cdot 0-100$ \\
2 & 0 & 26 & $97 \cdot 1$ & $83 \cdot 4-100$ \\
Total & 18 & 33 & & \\
\hline
\end{tabular}

CI, Confidence interval.

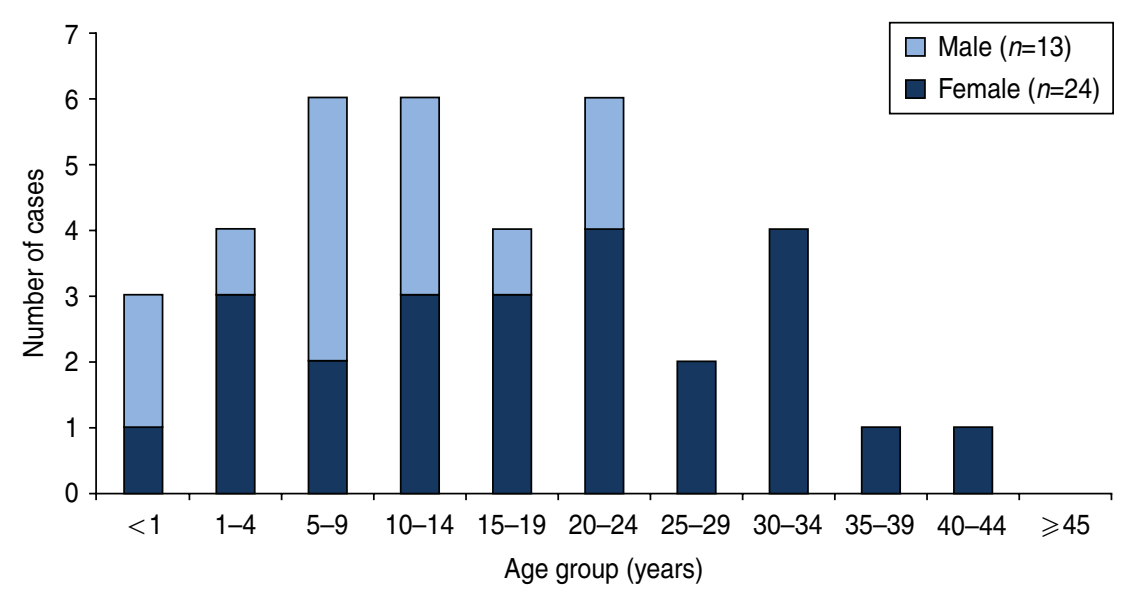

Fig. 2 [colour online]. Age and sex distribution of community cases in district X measles outbreak, Berlin, Germany, 2011 $(n=37)$.

Of 32 community case-patients with known vaccination status $27(84 \%)$ were unvaccinated, five (16\%) had received one dose and none had received two doses of MCV. Four case-patients had received vaccination $\geqslant 21$ days before disease onset. One casepatient had received MCV1 as a post-exposure vaccination 4 days after symptom onset of his sibling and developed measles disease 10 days after the vaccination. District of residence was known for 36/39 case-patients: $31(86 \%)$ lived in district $\mathrm{X}$ and five $(14 \%)$ lived in three other districts of Berlin, but worked or went to school in district X. Number of days from onset of symptoms to notification at the local health authorities $(n=23)$ ranged from 3 to 23 days (median 8 days). Number of days from diagnosis to notification at the local health authority $(n=18)$ ranged from 0 to 9 days (median 1 day).

\section{School-trip cases}

Twenty of 55 school-trip participants developed measles. The primary case-patient, child A, had symptom onset (fever, cough and runny nose) on the third day of the 4-day trip, the first week of the peak in the number of community cases, which suggests exposure in the community (Fig. 1). Child A had rash onset in week 18. All other school-trip casepatients developed rash 8-13 days after child A's rash onset. Case-patients were aged 7-10 years and eight $(42 \%)$ of 19 with known gender were female. No hospitalizations were reported for the school-trip case-patients. Of the 20 students with probable and confirmed measles, 18 were unvaccinated and vaccination status was unknown for two. Of the remaining 35 school-trip participants, 26 (74\%) had received two doses of MCV, six (17\%) had received one dose, one $(3 \%)$ had received no vaccination and two $(6 \%)$ had unknown vaccination status (Table 1). After excluding students with unknown vaccination status, the AR was $94 \%(18 / 19)$ in unvaccinated students. No cases occurred in vaccinated students (one or two doses). Based on the IRR, VE for MCV1 was estimated at $87 \cdot 6 \%(95 \%$ CI $28 \cdot 0-100)$ and $\mathrm{VE}$ for MCV2 at $97 \cdot 1 \%(95 \%$ CI $83 \cdot 4-100)$. 


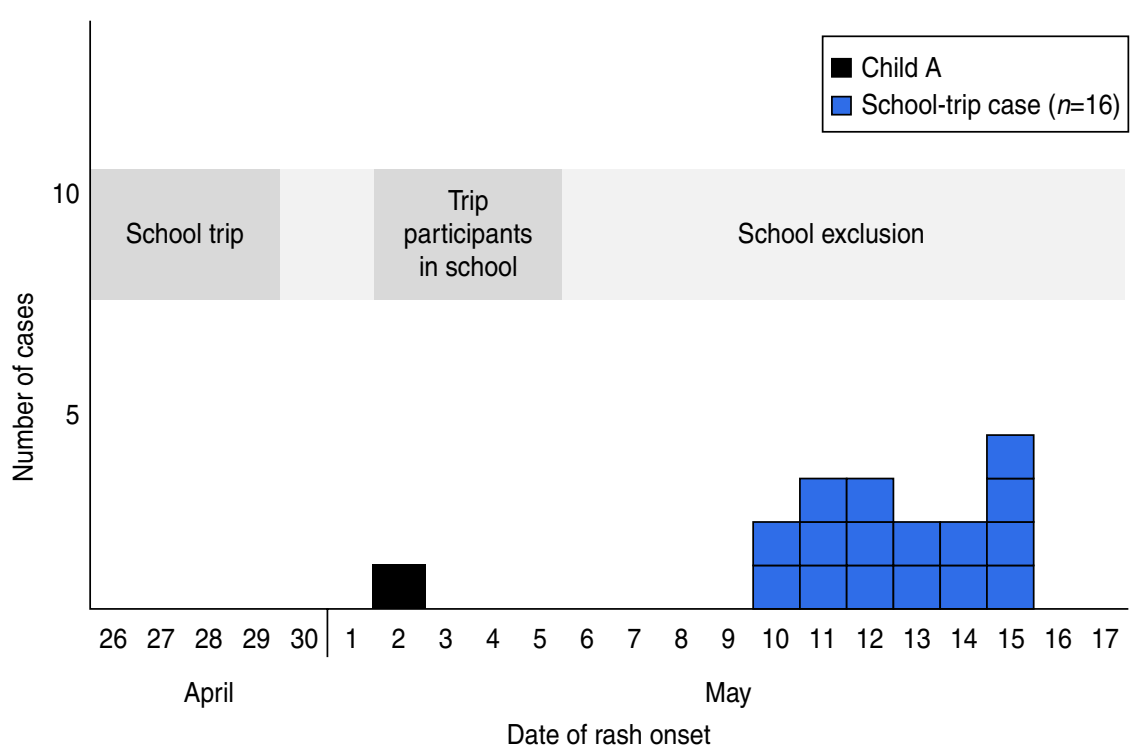

Fig. 3 [colour online]. School-trip cases in district X measles outbreak, Berlin, Germany, 2011, by date of rash onset $(n=17)$.

\section{Laboratory results}

Of the 73 case-patients, $38(52 \%)$ were laboratory tested and the result known. All were positive for acute measles infection. Eight (11\%) were laboratory tested but with unknown result. MV genotyping was successful for 26 cases: community case-patients $(n=6)$, school-trip case-patients $(n=14)$ and their secondary cases $(n=6)$; all had the same variant of MV genotype D4 (MVs/Berlin.DEU/18.11). In the 450 nucleotide sequence used for genotyping this MV variant was identical to MVs previously detected in France (i.e. MVs/Toulon.FRA/03.11, MVs/ClermontFerrand.FRA/09.11) and a MV that was imported to Slovenia from France (MVs/ Ljubljiana.SVN/15.11) [19]. At the time of the outbreak investigation, a MV variant exhibiting sequence identity to MVs/Berlin.DEU/18.11 was not detected in any other measles case in Germany.

\section{Control measures}

The district health authorities checked the vaccination cards of families and at schools and nurseries with one or more children with measles, announced school/ nursery/work exclusions, gave recommendations on post-exposure vaccinations and sent information letters to local doctors and schools informing them of the outbreak and reminding them of their notification duty and the measles management guidelines. The local population was informed through a press release.

On 2 May 2011, the Monday following the school trip, the children attended school except child A, who on that day had developed a rash $(<4$ days after returning from the school trip) (Fig. 3). The diagnosis of measles was confirmed and reported to the school on 5 May. On the same day, the school informed parents of children who participated in the trip. All school-trip participants without documented vaccinations were excluded from school. However, the children had attended school until 7 days after the first exposure to measles. The second case among school-trip participants had symptoms and rash onset after the implementation of the school exclusion and no other case occurred in students not attending the school trip.

Vaccination cards of all students were checked in order to assess the vaccination coverage and possible extent of a measles outbreak at the school and to plan for appropriate control measures in case the exclusion of school-trip participants had been introduced too late. Of the 381 students, $95(25 \%)$ were unvaccinated before the outbreak, $95(25 \%)$ had unknown vaccination status, $65(17 \%)$ had one vaccination, $121(32 \%)$ had two vaccinations, and five $(1 \%)$ had a documented history of measles. After being informed of the outbreak, parents of 34 students took their child to be vaccinated at a private physician during May 2011: 24 students received their first dose and 10 their second dose of MCV.

\section{DISCUSSION}

The outbreak investigation showed that district $\mathrm{X}$ experienced a single outbreak of measles with 
73 probable and confirmed case-patients between April and July 2011 caused by MVgenotype D4 (MVs/Berlin.DEU/18.11). Child A was exposed to measles in the community and introduced it to schooltrip participants from an anthroposophic school. This was the largest measles outbreak in Berlin since the introduction of the electronic notification system in 2001 . Of community case-patients, $38 \%$ were aged $\geqslant 20$ years. Hospitalizations occurred in the very young and adult case-patients. Of school-trip participants, none of the vaccinated children developed measles despite being exposed through shared activities, e.g. sitting on the same bus for several hours. This translates into a very high MCV2 VE. Except for school-trip participants, no additional cases of measles were identified at the school despite the high proportions of unvaccinated students and students with unknown vaccination status. The exclusion of unvaccinated school-trip participants as late as 7 days after first exposure was thus an effective control measure in this setting.

We found a two-dose VE of $97 \cdot 1 \%$ which corresponds with the two-dose VE of $99 \cdot 4 \%$ (95\% CI 97-100) reported from a large school outbreak in Germany in 2006 [20] and a VE found in a review of field effectiveness of MCVs (two-dose VE 94.1\%, 95\% CI 88.3-98.3) [21]. The MCV1 VE estimation was limited by the low number of children with one vaccination resulting in a wide $95 \%$ CI.

The WHO recommends a $95 \%$ MCV2 coverage to eliminate measles from the WHO European region by 2015 [1,22] in order to hinder community outbreaks caused by accumulation of susceptible individuals. Measles vaccination is voluntary in Germany and differences exist between federal states (lowest coverage in Southwest Germany), between districts within federal states and can be particularly low in specific local settings such as anthroposophic schools. In district $\mathrm{X}$ and overall in Berlin, MCV2 coverage has not reached the target of $95 \%$. The below target coverage and the results of our study highlight the fact that vaccination coverage in local settings (e.g. schools) can be far below the state level, which can be a source or multiplier for localized outbreaks.

The outbreak described here was not the first outbreak in Berlin in recent years. Berlin experienced an outbreak in a population with critical attitudes towards vaccination in 2010 with at least 62 cases with a mean age of $10 \cdot 5$ years [11]. A measles seroprevalence study of children and adolescents aged $0-17$ years in Germany enrolled between May 2003 and May 2006, found that $7 \cdot 7 \%$ of 10 - to 17 -year-olds were seronegative for measles [23]. The low vaccination coverage for MCV2, the estimated high proportion of seronegatives among adolescents, as well as the recent outbreaks are signs of pockets of susceptible individuals in the adult and anthroposophic population of district $\mathrm{X}$ and Berlin. This outbreak thus showed that pockets of susceptible people continue to be present in Germany, as also seen in previous outbreaks [24-26]. Additionally, adult women seem to be at higher risk of measles infection, which may be due to either more exposure through contact with children or less catch-up possibilities than men, who are more likely to be vaccinated through military service.

This outbreak investigation confirmed that two doses of MCV are highly effective in preventing measles disease. Therefore the outbreak was not due to vaccination failure, but due to low vaccination coverage, which also applied to affected adults. The introduction of a two-dose schedule in 1991 and increasing vaccination coverage of later birth cohorts diminished the circulation of $\mathrm{MV}$, thus reducing chances of exposure to the virus for later generations. However, a considerable proportion of adults aged 20-40 years, i.e. birth cohorts from around 1970-1990 are still susceptible, which can be explained by low vaccination coverage in the first two decades of infant measles immunization. This supports the recommendation of administering a catch-up MCV1 or MCV2 to everyone born after 1970 with incomplete or unknown vaccination status.

Genotyping and further genetic subtyping confirmed that all case-patients living in district $X$ and case-patients working or attending school in district $\mathrm{X}$ were indeed part of the outbreak. MV variants of genotype D4 have caused outbreaks in Europe since 2007 and D4 became the predominant genotype in Europe in $2011[4,27]$. The MV variant responsible for the outbreak in district $\mathrm{X}$ circulated in France during the first and second quarters of 2011 [19]. No other case of this MV variant was identified in Germany prior to the outbreak investigation. This indicates that the outbreak was probably initiated by introduction of the MV from another country. The source of MV importation is unknown since the index case could not be identified.

Laboratory testing of suspected measles casepatients is not mandatory in Germany. The costs are, however, covered by the NRC. In the past, it was documented that underreporting as well as 
delayed diagnosis and reporting of measles is not uncommon in Germany [28]. We identified casepatients using notification data and active case finding and identified five community case-patients living in other districts in Berlin. However, after closure of the outbreak investigation 11 additional case-patients with detection of the sequence MVs/ Berlin.DEU/18.11 and disease onset before 31 July 2011 were identified at the NRC. Eight were living in Berlin. Three were living in another federal state and were probably infected by a relative living in Berlin. We were, however, unable to establish district $\mathrm{X}$ as the place of infection. The temporal distribution suggests that these 11 cases belong to the transmission chain initiated by the MV spread in district $\mathrm{X}$. The presence of obviously existing unrecognized epidemiological links between cases in Berlin highlights the importance of laboratory investigations and communication between different district health authorities and the laboratory as well as active case finding when investigating a community outbreak.

In this outbreak, $27 \%$ of all case-patients and 38\% of community case-patients were aged $\geqslant 20$ years. The general shift towards older age groups reported in outbreaks in Germany since 2001 [10] is thus seen for the community where it was similar to the $35 \cdot 2 \%$ reported for Europe in 2011 [4]. The overall proportion of $15 \%$ hospitalized cases in this outbreak was lower than in Europe in 2011, where the proportion was $28 \%$ [4]; however, in community cases $63 \%$ were hospitalized.

The delayed case notification made it difficult to implement control measures. For community casepatients risk of transmission was also seen as some cases were sent home with an initial diagnosis of an allergic reaction or were hospitalized for several days without a measles diagnosis.

Exclusion from school of unvaccinated school-trip participants was delayed by late reporting of the measles diagnosis of child A until day 8 after exposure. Thanks to the swift reaction of the school doctor and school directorate, exclusion was implemented in time to avoid secondary cases in students not participating in the trip. Given the low vaccination coverage of the pupils at the school and the reproduction rate of measles, this exclusion may have prevented up to 190 additional cases in students with unknown vaccination status or known to be unvaccinated. Additionally, the information on the outbreak increased the number of students who received one or two doses of $\mathrm{MCV}$.

\section{RECOMMENDATIONS}

In order to achieve measles elimination in Germany by 2015, vaccination coverage in children, adolescents, and young adults needs to be improved. This requires information and promotion campaigns targeted both at the public and at primary-care physicians including occupational health doctors and gynaecologists who see adolescent and adult patients. Physicians need to be reminded of the importance of rapid laboratory diagnosis and notification of suspected measles case-patients in order to allow timely implementation of control measures. School exclusion of exposed unvaccinated individuals is an important intervention even after occurrence of a single case in order to interrupt transmission of measles, especially in communities with low vaccination coverage or reluctance to implement immediate mass vaccination in response to the outbreak. Surveillance including MV genotyping should be continued during outbreaks to assess the circulation period of an imported MV.

\section{ACKNOWLEDGEMENTS}

We thank all district health authorities (Gesundheitsämter) in Berlin, who provided information on cases with residency in their district. We also thank the affected school for cooperation. Additionally, we thank colleagues at RKI; Dr Annicka Reuß, EPIET coordinator Dr Ioannis Karagiannis and EPIET statistician Manuel Dehnert for their technical assistance. Furthermore, we are grateful to all the people we interviewed when investigating this outbreak for their participation and collaboration without which we would not have been able to conduct this investigation. This research received no specific grant from any funding agency, commercial or not-for-profit sectors.

\section{DECLARATION OF INTEREST}

None.

\section{REFERENCES}

1. World Health Organization. Eliminating Measles and Rubella: Framework for the Verification Process in the WHO European Region. Copenhagen: World Health Organization, European Regional Office, 2012.

2. Regional Committee for Europe. Resolution: Renewed commitment to elimination of measles and rubella and prevention of congenital rubella syndrome by 2015 , 102585 (2010).

3. Muscat M, et al. Measles in Europe: an epidemiological assessment. Lancet 2009; 373: 383-389. 
4. World Health Organization. Increased transmission and outbreaks of measles, European Region, 2011. Weekly Epidemiological Record 2011; 49: 559-564.

5. Huoi C, et al. A report on the large measles outbreak in Lyon, France, 2010 to 2011. Eurosurveillance 2012; 17: 20264.

6. Vivancos R, et al. An ongoing large outbreak of measles in Merseyside, England, January to June 2012. Eurosurveillance 2012; 17: pii $=20226$.

7. SurvStat. Robert Koch-Institut (http://www3.rki.de/ SurvStat/). Accessed 26 February 2013.

8. Siedler A, et al. Closer to the goal: efforts in measles elimination in Germany 2010. Journal of Infectious Diseases 2011; 204 (Suppl. 1): S373-380.

9. Robert Koch-Institut. Annual report of notifiable infectious diseases for 2010. Berlin: Robert Koch-Institut, 2011.

10. Robert Koch-Institut. Modification of the vaccination recommendations against measles. Epidemiologisches Bulletin 2010; 32: 315-322.

11. Bätzing-Feigenbaum J, et al. Spotlight on measles 2010: preliminary report of an ongoing measles outbreak in a subpopulation with low vaccination coverage in Berlin, Germany, January-March 2010. Eurosurveillance 2010; 15: pii $=19527$.

12. Bundesgesundheitsblatt. Vaccination recommendations of the German Standing Committee on Vaccination (STIKO), effective: July 1991. Bundesgesundheitsblatt 1991; 8: $384-388$.

13. Robert Koch-Institut. Vaccination coverage at school entry health examinations in Germany 2010. Epidemiologisches Bulletin 2012; 16: 135-139.

14. Robert Koch-Institut. Recommendations of the Standing Committee on Vaccination (STIKO) at the Robert Koch Institute, effective: July 2010. Epidemiologisches Bulletin 2010; 30: 279-298. [in German, English version available at: www.stiko.de/en).

15. Tischer A, et al. Laboratory investigations are indispensable to monitor the progress of measles eliminationresults of the German Measles Sentinel 1999-2003. Journal of Clinical Virology 2004; 31: 165-178.

16. World Health Organization. Measles virus nomenclature update: 2012. Weekly Epidemiological Record 2012; 87: 73-80.
17. Santibanez S, et al. Rapid replacement of endemic measles virus genotypes. Journal of General Virology 2002; 83: 2699-2708.

18. Mankertz A, et al. Spread of measles virus D4Hamburg, Europe, 2008-2011. Emerging Infectious Diseases 2011; 17: 1396-1401.

19. World Health Organization. Global measles genotype database. World Health Organization, Geneva, Switzerland, 2011.

20. Wichmann O, et al. Large measles outbreak at a german public school, 2006. Pediatric Infectious Disease Journal 2007; 26: 782-786.

21. Uzicanin A, Zimmerman L. Field effectiveness of live attenuated measles-containing vaccines: a review of published literature. Journal of Infectious Diseases 2011; 204 (Suppl. 1): 133-148.

22. World Health Organization. Renewed commitment to measles and rubella elimination and prevention of congenital rubella syndrome in the WHO European Region by 2015. Moscow: World Health Organization Regional Office for Europe, 2010.

23. Poethko-Muller C, Mankertz A. Sero-epidemiology of measles-specific IgG antibodies and predictive factors for low or missing titres in a German population-based cross-sectional study in children and adolescents (KiGGS). Vaccine 2011; 29: 7949-7959.

24. Roggendorf H, et al. Two consecutive measles outbreaks with genotypes D8 and D4 in two mainly unvaccinated communities in Germany. Medical Microbiology and Immunology 2012; 201: 349-355.

25. Wadl M, et al. Measles transmission from an anthroposophic community to the general population, Germany 2008. BMC Public Health 2011; 11: 474.

25. Hegasy G, et al. Description of measles D4-Hamburg outbreak in Hamburg, Germany, December 2008 to June 2009, which disproportionally affected a local Roma community. Eurosurveillance 2012; 17: pii $=20194$.

27. Rota PA, et al. Global distribution of measles genotypes and measles molecular epidemiology. Journal of Infectious Diseases 2011; 204: 514-523.

28. Mette A, et al. Under-reporting of measles: an evaluation based on data from north Rhine-Westphalia. Deutsches Ärzteblatt International 2011; 108: 191-196. 